\title{
Community empowerment through improvements skills and health promotions on refugees in the Medan district of Selayang
}

\author{
Devi Nuraini Santi ${ }^{1 *} \&$ Halinda Sari Lubis ${ }^{2}$ \\ ${ }^{1}$ Departemen Kesehatan Lingkungan Fakultas Kesehatan Masyarakat, USU \\ ${ }^{2}$ Departemen Kesehatan dan Keselamatan Kerja Fakultas Kesehatan \\ Masyarakat,USU \\ *Email: devi@usu.ac.id
}

\begin{abstract}
Empowerment means empowering a person because he is considered to be helpless or very small, so that he can hardly do anything, women refugees need to be empowered by providing skills that produce economic value and filling free time aimed at reducing levels stress on refugees. One that can be used as a skill material is the production which is currently experiencing an increase in patchwork waste. There were 182 refugees in Medan Selayang Subdistrict, and 52 adult women in particular. The principle of service that will be carried out for partners in Kost YPAP refugee camps is to provide health promotion, guidance and skills in processing patchwork into economic value goods, so that refugees have skills that can be applied while in refugee with economic value and can reduce stress on refugees. The Community Service Team conducted socialization on the empowerment of refugee women specifically in producing accessories from varied patchwork and beads as well as health promotion in reducing stress levels due to lack of activity and limited activities on refugees. Furthermore, the Community Service Team conducts training to improve knowledge and skills in order to obtain high sales value in the community and its marketing is assisted by the Social Service and the National Conference in Medan.
\end{abstract}

Keywords: Women Refugees, Accessories, Patchwork, Beads

\begin{abstract}
Abstrak
Pemberdayaan atau empowerment berarti pemberian daya atau kekuatan kepada seseorang karena dia dianggap tidak berdaya atau kekuatan sangat kecil, sehingga hampir tidak dapat berbuat apaapa, pada pengungsi wanita perlu diberdayakan dengan memberi keterampilan yang menghasilkan nilai ekonomis dan mengisi waktu luang yang ditujukan untuk mengurangi tingkat stress pada pengungsi. Salah satu yang dapat digunakan sebagai bahan keterampilan yaitu dengan produksi yang saat ini mengalami peningkatan limbah kain perca. Pengungsi yang berada di Kecamatan Medan Selayang Kota Medan berjumlah 182 orang dan khusus wanita dewasa berjumlah 52 orang. Prinsip pengabdian yang akan dilaksanakan pada mitra di pengungsian Kost YPAP adalah memberikan promosi kesehatan, bimbingan dan keterampilan mengolah kain perca menjadi barang bernilai ekonomis, sehingga para pengungsi mempunyai keterampilan yang dapat di aplikasikan selama berada dipengungsian yang bernilai ekonomis dan dapat mengurangi stress pada pengungsi. Tim Pengabdian melakukan sosialisasi tentang pemberdayaan wanita pengungsi khusus dalam memproduksi aksesoris dari kain perca dan manik-manik yang bervariasi serta promosi kesehatan dalam mengurangi tingkat stres dikarenakan kurang aktifitas serta terbatasnya kegiatan pada pengungsi. Selanjutnya Tim Pengabdian melakukan pelatihan untuk meningkatkan pengetahuan dan keterampilan agar diperoleh nilai jual yang tinggi dimasyarakat dan pemasarannya dibantu oleh Dinas Sosial dan Dekranas yang ada di Kota Medan.
\end{abstract}

Kata Kunci: Pengungsi Wanita, Aksesoris, Kain Perca, Manik-manik 


\section{PENDAHULUAN}

Aksesoris merupakan suatu benda yang kerap sekali digunakan oleh seseorang sebagai tambahan atau mendukung keindahan dalam berpakaian, dengan bentuk yang beragam dan kerap dikaitkan dengan gender pemakainya. Jenis aksesoris bermacam-macam, seperti perhiasan (anting-anting, kalung, gelang dan bros), selendang, sabuk, suspender, dasi, syal, sarung tangan, tas, topi, arloji, kacamata dan pin. Busana tradisional memiliki aksesori khas yang biasanya dikenakan sebagai perlambang tertentu, seperti destar, sindur, tusuk konde, kembang goyang, dan keris (Wikipedia, 2018).

Aksesoris wanita digunakan sebagai penyempurna dari penampilan serta mencerminkan keperibadiannya, aksesoris tidak digunakan untuk menutupi kecantikan yang sudah ada tetapi justru meningkatkan dan menambah kecantikan itu sendiri (Rifa'atul, 2016). Salah satu material yang digunakan dalam membuat aksesoris adalah limbah sisa kain yang tidak dimanfaatkan lagi atau sering disebut dengan kain percah. Salah satu pemanfaatan kain percah adalah produk kerajinan aksesoris busana seperti kalung, hiasan sanggul, hiasan hijab, bros, pita rambut, bandana, gelang dan anting. Pemanfaatan kain perca selama ini hanya sebatas pembuatan sprei, sarung bantal, taplak meja dan keset kaki. Tetapi sangat jarang digunakan pada aksesoris pelengkap busana, sehingga dengan memanfaatkan kain percah diharapkan dapat mengurangi dampak pencemaran lingkungan yang disebabkan oleh hasil dari sisa produksi home industri dan dapat meningkatkan perekonomian dalam usaha rumah tangga.

Informasi dari Deputi Komunikasi Lingkungan dan Pemberdayaan Masyarakat Kementrian Lingkungan Hidup (2009), dalam mengelola sampah atau limbah dapat ditangani dengan mengurangi volume sampah, menggunakan kembali barang yang telah dipakai, dan mendaur ulang sampah supaya menjadi barang seperti semula atau menjadi barang lain atau baru. Menurut penelitian Armaini tahun 2015 hasil perhitungan penjahit jika kain percah dengan bahan polos seberat $1 \mathrm{~kg}$ akan menghasilkan 35 buah assesoris dengan harga Rp. 5.000,- sampai Rp. 8.000,-, kalung 6 buah dengan harga Rp. 35.000,- dan bros sebanyak 7 buah dengan harga Rp. $10.000,-$. Sementara kain lace dapat menghasilkan 6 buah kalung yang dapat dijual seharga Rp125.000,-, hiasan jilbab 5 buah dengan harga Rp. 35.000,- sampai Rp. 75.000,-, hiasan sanggul 4 buah dengan harga Rp. 35.000,-, dan hiasan jilbab berukuran besar 2 buah dengan harga Rp. 200.000,- sampai Rp. 300.000,-. Dari hasil capaian produk aksesoris yang telah diselesaikan menggambarkan bahwa produk aksesoris sudah diminati.

Pemberdayaan atau empowerment berarti pemberian daya atau kekuatan kepada seseorang karena dia dianggap tidak berdaya atau kekuatan sangat kecil, sehingga hampir tidak dapat berbuat apa-apa (Marzuki Saleh, 2010). Kasus sebagai tragedi kemanusiaan sudah berlangsung selama beberapa tahun. Dengan peningkatan intensitas publikasi dan jumlah pengungsi lintas negara, pengaruh konflik pada negara pengungsi tidak hanya pada level domistik, melainkan sudah memberikan pengaruh dan menjadi isu regional bahkan internasional.

Terdapat 6 titik lokasi pengungsian di Kecamatan Medan Selayang, tetapi yang menjadi lokasi pengabdian terfokus pada Kost YPAP yang terletak di Jalan Bunga Cempaka, Kelurahan Padang Bulan Selayang II. Jumlah total pengungsi yang berlokasi di Kecamatan Medan Selayang Kota Medan sebanyak 182 pengungsi, yang terdiri dari Wanita Dewasa berjumlah 52, Anak Perempuan sebanyak 36, Laki-laki Dewasa berjumlah 56, dan Anak Laki-laki sebanyak 38. Pengungsi yang berada di Kecamatan Medan Selayang terdiri ada Negara Sri Langka sebanyak 27 pengungsi, 
Myanmar sebanyak 65 pengungsi, Afghanistan sebanyak 22 pengungsi, Irak sebanyak 35 pengungsi, dan Sudan sebanyak 2 pengungsi. Banyak pengungsi yang tidak bekerja dan terbatas dalam beraktifitas membuat pengungsi cendrung mengalami jenuh dan stress sehingga perlu diberikan promosi kesehatan untuk mengurangi tingkat stress pada pengungsi. Selain itu pengungsi mempunyai waktu luang yang cukup banyak untuk dapat diberdayakan dalam membuat keterampilan aksesoris (gelang, kalung, anting-anting dan bros) yang memiliki nilai jual tinggi.

\section{METODE PELAKSANAAN}

Metode pendekatan yang dilakukan selama melakukan pengabdian kepada pengungsi wanita adalah dengan cara melakukan pelatihan, bimbingan dan pendampingan terhadap mitra. Peningkatan pengetahuan dan keterampilan pada pengungsi wanita dalam mengolah dan memproduksi limbah kain perca menjadi aksesoris yang bervariasi. Kurangnya pengetahuan pada pengungsi wanita dalam memproses kain perca mulai dari pemilihan kain perca, penyiapan bahan, pengolahan, dan pemasaran. Untuk meningkatkan pengetahuan dan keterampilan pengungsi wanita dilakukan dengan metode ceramah, diskusi dan demonstrasi. Melalui kegiatan pengabdian ini pengungsi wanita juga diharapkan mau dan mampu menerapkan pengolahan kain perca dan manik-manik secara berkelanjutan serta tingkat stress pada pengungsi dapat berkurang dengan adanya aktifitas keterampilan dilokasi pengungsian.

Memfasilitasi sarana dan prasarana untuk meningkatkan pengolahan pembuatan aksesoris yang bervariasi serta pemasaran aksesoris yang dihasilkan. Dilakukan kerjasama dengan Dinas Sosial, Dekranas dansektor terkait lainnya.

Kegiatan yang dilakukan untuk pemecahan masalah antara lain:

1. Sosialisasi kegiatan promosi kesehatan sebagai upaya penurunan tingkat stress pada pengungsi dalam memanfaatkan keterbatasan aktifitas dan menggunakan waktu luang yang ada.

2. Sosialisasi kegiatan pengabdian yaitu penjelasan tentang rencana pelatihan peningkatan pengetahuan dan keterampilan pada pengungsi wanita dalam memanfaatkan, mengolah kain perca dan manik-manik menjadi kerajinan tangan berupa aksesoris (kalung, gelang, anting-anting dan bros jilbab) yang lebih menarik dan bervariasi. Sosialisasi kegiatan pengabdian diberikan kepada pengungsi wanita yang berada di Kecamatan Medan Selayang Kota Medan agar paham tentang makna dan tujuan adanya kegiatan pengabdian. Selain itu sosialisasi ini juga akan membentuk suatu sikap dan keinginan untuk mau terlibat penuh dalam kegiatan pengabdian. Berdasarkan hal ini maka pelaksanaan kegiatan berjalan dengan baik.

3. Rekrut pengungsi wanita yang berada pada Kecamatan Medan Selayang Kota Medan untuk mengikuti pelatihan sebagai peserta kegiatan. Rekrut dilakukan setelah sosialisasi kegiatan. Pengungsi wanita yang tertarik mengikuti kegiatan pengabdian akan ditanyakan kesediaan dan komitmennya oleh tim pengabdian masyarakat USU untuk menjadi peserta kegiatan.

4. Pelaksanaan pelatihan tentang peningkatan pengetahuan dan keterampilan pada pengungsi wanita dalam memanfaatkan, mengolah serta memproduksi kain perca dan manik-manik menjadi aksesoris yang bervariasi dan unik. Pelatihan tentang peningkatan pengetahuan mitra dalam memanfaatkan limbah kain perca dan manik-manik untuk diolah menjadi aksesoris yang bervariasi. Pelatihan ini 
diperlukan untuk memberikan tingkat pemahaman yang baik tentang maksud dan pelaksanaan kegiatan pengabdian.

5. Pembentukan kelompok pengungsi wanita pengolah limbah kain percah dan manik-manik menjadi aksesoris yang bervariasi dan unik. Pelaksanaan kegiatan pengabdian ini dilakukan selama 6 bulan dimulai dari pengurusan ijin kegiatan, sosialisasi, rekrut, pelatihan, dan evaluasi. Dalam kurun waktu 2 bulan setelah pelatihan ini, tim pengabdian akan menanyakan kepada pengungsi wanita terkait dengan kendala ataupun masalah yang dijumpai dalam pelaksanaan pengolahan, produksi dan pemasaran aksesoris berbahan limbah kain perca dan manik-manik.

6. Pemasaran usaha kerajinan berbahan dasar limbah kain perca dan manik-manik bekerjasama dengan Dinas Sosial, Dekranas dan sektor terkait lainnya. Pembuatan limbah kain perca dan manik-manik menjadi aksesoris yang bervariasi dilakukan di lokasi pengungsian yang dilakukan oleh tim pengabdian dan wanita pengungsi, setelah produksi selesai akan dilakukan kerjasama dengan Dinas Sosial, Dekranas, dan sektor terkait lainnya agar lebih diketahui masyarakat.

7. Evaluasi kegiatan berdasarkan pelaksanaan kegiatan pengolahan, produksi dan pemasaran aksesoris berbahan kain perca dan manik-manik. Evaluasi kegiatan dilakukan oleh tim pengabdian masyarakat USU berdasarkan masukan, saran, dan permasalahan nyata yang dijumpai oleh pengungsi wanita selama pelaksanaan kegiatan pelatihan. Bila diperlukan, permasalahan tersebut akan disampaikan kepada Dinas Sosial, Dekranas dan sektor terkait lainnya. Salah satu contoh tindak lanjut berdasarkan evaluasi kegiatan pemeriksaan secara berkala kegiatan peningkatan produksi dan pemasaran aksesoris berbahan kain perca dan manikmanik.

Kegiatan pengabdian masyarakat ini dilaksanakan oleh tim Pengabdian Masyarakat yang terdiri dari dosen Fakultas Kedokteran Universitas Sumatera Utara kepada siswa kelas IV hingga VI SDN 040494 Desa Susuk, Kecamatan Tiganderket, Kabupaten Karo. Kegiatan yang dilaksanakan dibagi menjadi dua tahap yaitu penyuluhan, pelatihan kesehatan dan diseminasi. Pada tahap awal, tim pengabdian kepada masyarakat melakukan penyuluhan kesehatan dibantu oleh mahasiswa FK USU. Kegiatan ini terintegrasi dengan mata pelajaran Pendidikan Jasmani yang sudah dimulai dari kelas 1 sekolah dasar. Siswa kelas 4, 5 dan 6, selain dikenalkan PHBS juga diajarkan cara mencuci tangan dan pemilihan makanan sehat. Di akhir kegiatan, akan diumumkan dokter kecil yang akan bertugas selama satu tahun ke depan. Materi yang diberikan berupa PHBS dan pemilihan makanan sehat. Selanjutnya dilaksanakan pelatihan yang ditujukan sebagai upaya pertolongan pertama pada masalah kesehatan yang timbul. Kegiatan ini bertujuan untuk melatih siswa agar dapat melaksanakan sebagian upaya pemeliharaan dan peningkatan kesehatan terhadap diri sendiri, teman, keluarga dan lingkungannya. Di akhir kegiatan pada masyarakat, dlaksanakan pemilihan dokter kecil dimana peserta kegiatan adalah siswa kelas 4, 5 dan 6 yang telah menerima penyuluhan dan pelatihan sebelumnya.

\section{HASIL DAN PEMBAHASAN}

Sosialisasi kegiatan promosi kesehatan sebagai upaya penurunan tingkat stress pada pengungsi dalam memanfaatkan keterbatasan aktifitas dan menggunakan waktu luang yang ada. 
Sosialisasi kegiatan pengabdian diberikan kepada pengungsi perempuan YPAP kecamatan Medan Selayang pada tanggal 17 Juli 2019 yaitu penjelasan tentang rencana pelatihan peningkatan pengetahuan dan keterampilan pada pengungsi wanita dalam memanfaatkan, mengolah kain perca dan manik-manik menjadi kerajinan tangan berupa aksesoris (kalung, gelang, anting-anting dan bros jilbab) yang lebih menarik dan bervariasi. Sosialisasi kegiatan pengabdian diberikan kepada pengungsi wanita yang berada di Kecamatan Medan Selayang Kota Medan, IOM dan Kepala Imigrasi Kemenkumham Sumatera Utara agar paham tentang makna dan tujuan adanya kegiatan pengabdian. Selain itu sosialisasi ini juga akan membentuk suatu sikap dan keinginan untuk mau terlibat penuh dalam kegiatan pengabdian. Berdasarkan hal ini maka pelaksanaan kegiatan berjalan dengan baik.

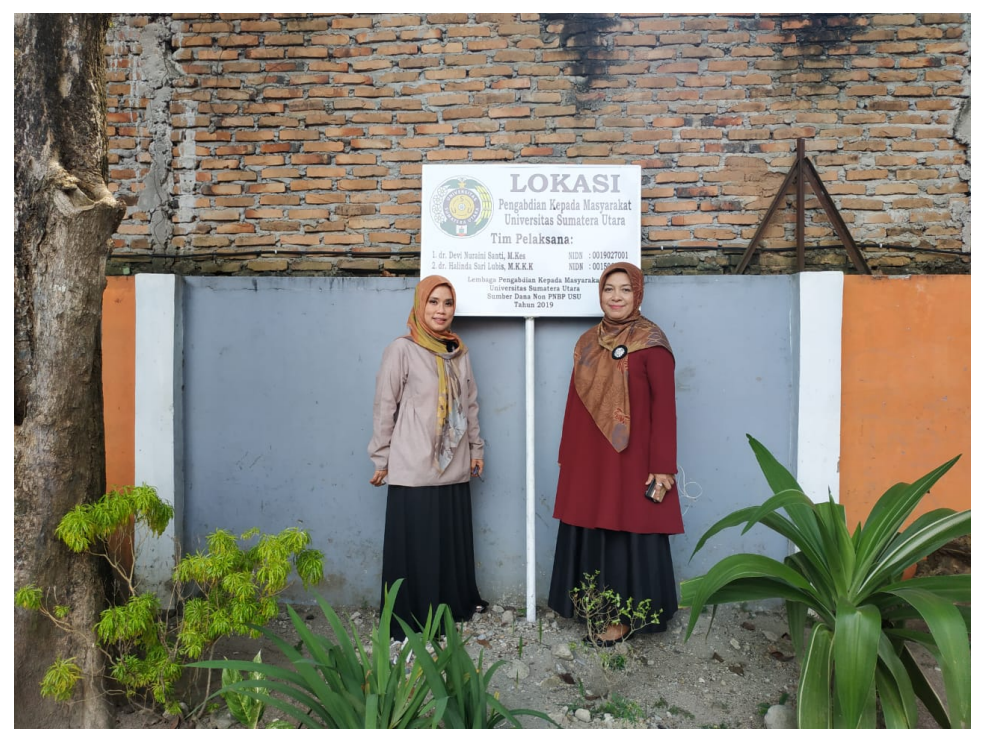

Gambar 3.1 Sosialisasi Kepada Imigrasi YPAP Medan Selayang

Melalui kegiatan pengabdian ini pengungsi wanita juga diharapkan dapat memanfaatkan keterbatasan aktifitas sebagai penyebab dari stress dapat berkurang dengan adanya kegiatan keterampilan seperti pembuatan aksesoris serta pengungsi mau dan mampu menerapkan pengolahan kain perca dan manik-manik secara berkelanjutan.

\subsection{Pelaksanaan kegiatan pengabdian}

Kegiatan pengabdian pada pengungsi YPAP Kecamatan Medan Selayang Kota Medan dilaksanakan pada tanggal 31 Juli Tahun 2019. Kegiatan diawali dengan penjelasan dari dr. Devi Nuraini Santi, M.Kes mengenai perilaku hidup bersih dan sehat (PHBS). Selanjutnya kegiatan dilanjutkan dengan pengolahan limbah kain perca dan manik-manik menjadi aksesoris yang bervariasi dan unik yang disampaikan oleh ibu Erlina Tarigan. 


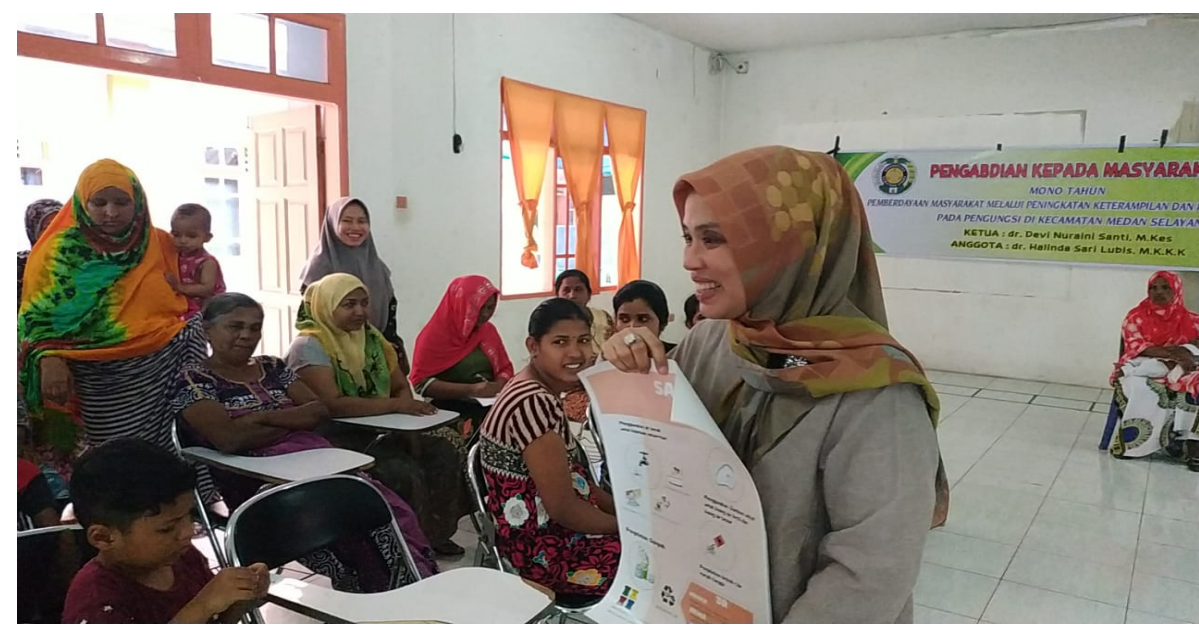

Gambar 3.2 Penjelasan mengenai PHBS

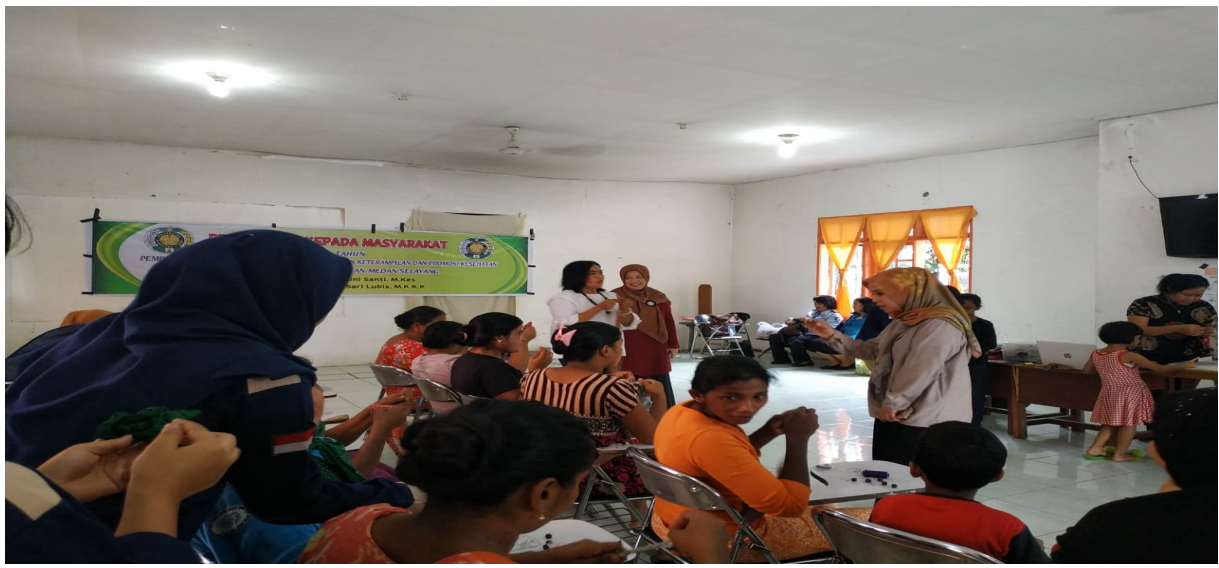

Gambar 3.3 Penjelasan Pengolahan Limbah kain perca menjadi berbagai manikmani

Pelaksanaan pelatihan tentang peningkatan pengetahuan dan keterampilan pada pengungsi wanita dalam memanfaatkan, mengolah serta memproduksi kain perca dan manik-manik menjadi aksesoris yang bervariasi dan unik.

Pelatihan tentang peningkatan pengetahuan mitra dalam memanfaatkan limbah kain perca dan manik-manik untuk diolah menjadi aksesoris yang bervariasi. Pelatihan ini diperlukan untuk memberikan tingkat pemahaman yang baik tentang maksud dan pelaksanaan kegiatan pengabdian. 


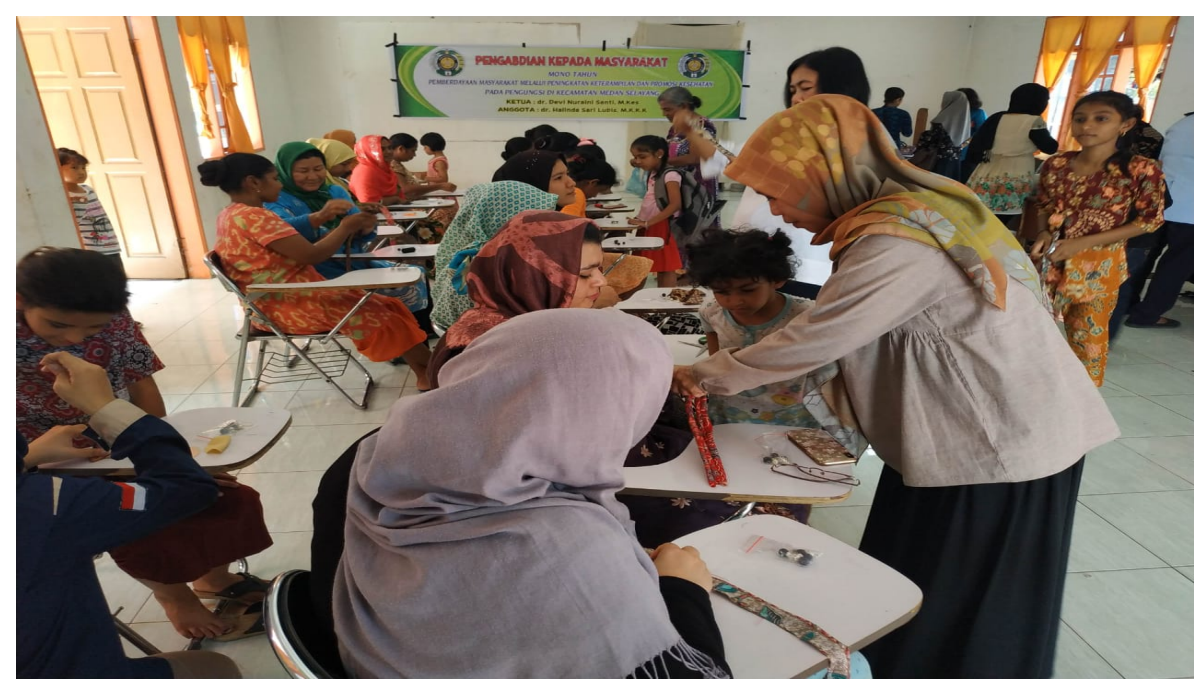

Gambar 3.4 Pelatihan pemanfaatan kain perca dan manik-manik menjadi aksesoris yang bervariasi dan unik

\section{KESIMPULAN}

1. Telah dilakukan sosialisasi mengenai pembuatan kerajinan berbahan dasar limbah kain perca dan manik-manik menjadi aksesoris yang bervariasi dan unik kepada pengungsi YPAP Kecamatan Medan Selayang.

2. Telah dilaksanakan Pelatihan Pembuatan Kerajinan kerajinan berbahan dasar limbah kain perca dan manik-manik kepada pengungsi YPAP Kecamatan Medan Selayang.

\section{UCAPAN TERIMAKASIH}

Artikel ini merupakan salah satu hasil dari Program Pengabdian kepada Masyarakat yang dibiayai oleh Lembaga Pengabdian Kepada Msyarakat Universitas Sumatera Utara tahun 2019 Skema Dosen Mengabdi. Oleh karena itu, diucapkan terima kasih kepada Rektor Universitas Sumatera Utara atas dukungan dana dan fasilitas yang diberikan. Terima kasih juga kepada Mitra pada kegiatan pengabdian ini.

Artikel ini merupakan salah satu hasil dari Program Pengabdian kepada Masyarakat Sumber Dana Non PNPB Universitas Sumatera Utara Sesuai dengan Surat Perjanjian Penugasan Pelaksanaan Program Pengabdian kepada Masyarakat Skim Dosen Mengabdi Tahun Anggaran 2019 Nomor: 785/ UN5.2.3.2.1/ PPM /2019, Tanggal 23 Juli 2019.

\section{DAFTAR PUSTAKA}

Armanini. (2015). IBM Usaha Penjahit Busana Wanita dalam Pembuatan Aksesoris dari Limbah Kain Perca. Jurnal Pengabdian Masyarakat, 21(82), 2-5. Diakses Maret 22, 2019 dari file:///C:/Users/HP/Downloads/3435-6435-1-PB.pdf

Khustiyana, Rifa'atul. (2016). Pelatihan Keterampilan Membuat Aksesoris Dari Bahan Dasar Kain Perca Dan Manik -Manik Bagi Eks Wanita Tuna Susila Pasca Penutupan Lokalisasi Jarak Surabaya. Jurnal Tata Rias, 5(1), 8-14. Diakses Maret 22, 2019 dari http://jurnalmahasiswa.unesa.ac.id/ index.php/jurnaltatarias/article/viewFile/15181/13747 
Maymunah. (2016, Oktober). Membuat Bros Bunga Dari Kain Percah. Diakses Maret 22, 2019 dari http://indo.amuslima.com/membuat-bros-bunga-dari-kain-perca/

Wikipedia. (2018). Aksesori. Diakses Maret 22, 2019 dari https://id.wikipedia.org/wiki/Aksesori

Yumitro, Gonda. (2017). Respon Dunia Internasional Terhadap Tragedi Kemanusiaan. Jurnal Sosial Politik, 3(2), 81-100. Diakses Maret 22, 2019 dari http://ejournal.umm.ac.id/index.php/sospol/article/view/4 